\title{
Discussion and Analysis on Chinese Ancient Biogenetics Thought
}

\author{
Jie Zeng \\ Institute of Marxism \\ Wuhan University of Science and Technology \\ Wuhan, Hubei, China 430065
}

\begin{abstract}
Among Chinese ancient scientific thoughts, many are precious and valuable, such as ancient biogenetics thought, which should be well explored and promoted. This article gives an introduction to the ancient people's understanding of biogenetics and variation, as well as the practice and application of ancient biogenetics thoughts, including artificial selection, crossbreeding and plant grafting.
\end{abstract}

\section{Keywords-ancient; biogenetics thought; genetic variation}

\section{INTRODUCTION}

China is one of the countries that had created the earliest civilization around the world; starting from the early ancient times, Chinese ancestors had started labor, made living and breeding on the earth; they trained themselves and created brilliant culture and science through labors. During the longterm collection, hunting and primitive agricultural and livestock production, they had accumulated various knowledge about the nature, which were the earliest understanding of biology. After thousands of years of production and practice in agriculture, animal husbandry and gardening, Chinese people have formed a certain understanding of the genetics and variation of animals and plants, of which, relevant knowledge are adopted to breed innumerable quality varieties of livestock and plants.

\section{CHINESE ANCIENT UNDERSTANDING OF BIOGENETICS AND VARIATION}

\section{A. Understanding of Biogenetics}

Biogentics is a basic characteristic for all creatures, which is common in the nature. The "Lyu's Annals Yong Min" (329 BC) written in the Warring States period said: "wheat is what we want through planting, and millet is what we want through planting, it is a natural rule" It proved that the ancient people had an initial understanding of the biogenetics stability. The "Lyuyu Jicui" said "if you want to gain bean, you have to plant bean seed; if you want to gain melon, you have to plant melon seed."; " Records of the States in the Eastern Zhou Dynasty" said: "gain melon with melon seeds, gain bean with bean seeds." These were specific descriptions about

Jie Zeng (1990 - ), male, Han ethnic group, native of Xiantao, Hubei province, postgraduate student of Wuhan University of Science and Technology, majoring in Philosophy of Science and Technology, Research Direction: Chinese philosophy and traditional culture. biogenetics by the ancient people.

The one who conducted the earliest researches on trait transmission between parents and offspring and obtained outstanding results should be Wang Chong in Eastern Han Dynasty (AD 27-97). He ever had a debate with his disciples. Wang Chong said: "The turtle gives birth to a turtle, the dragon gives a birth of a dragon, whether in size or color the parent is the same as his or her child, you can image the children by looking at parent, what is unknown?" ("Lunheng. Xiangrui") Wang Chong believed that genetic characteristics of biological parents (as color, shape, size, etc.) could be transmitted to next generations stably. Wang Chong called it "the individual of each species can inherit basic characteristics of previous generation". In "Lunheng. Strange"), Wang Chong said, "Everything is born in the soil, each is like the species of its own; those which are not soils cannot produce soil. A mother giving birh to a baby is like the soil producing goods....all things are born like the species of their own". This is, plants sprout in soil just like the species of their own. The reason why their nature is dislike soil is because their nature does not originate from the soil, which is only a carrier for them. After referring to "all things are born like the species of their own", Wang Chong added, "Animals who have blood will couple together, mating between male and female, but limited to the same species. Horse and cow, bird and chicken do not belong to the same species so they cannot have mating with each other".

Furthermore, Wang Chong knew that the biogenetics could not be separated from the life breeding, that is, the genetics of a variety of biological characteristics were usually achieved through seeds (germ cells). Wang Chong said, all things are born due to Qi, the species are raised by generations, all things on earth are continued through seeds". "The species are raised by generations" stated in ("Lunheng. Wushi") said, the traits of biological species are genetic, and the reproduction of all things is achieved through seed. It is true that the characteristics of the species transmitted to offspring are also achieved through seeds. Wang Chong said, "The king's fate has been confirmed during pregnancy of the mother, just like some people are born to be rich and male birds formed in eggs. Not only people and birds are like this, all things are so. Plants grow from seeds, after coming out of soil, they become young seedlings and sprout, gradually grow out stems and leaves, the 
seeds decide the length and size of the plants." ("Lunheng. Chubing").

\section{B. Understanding of Biological Variation}

Ancient people had realized not only the genetic phenomena of creatures, but also the biological variation. In early Zhou Dynasty, "Zhou Li" listed a variety of variant horses, such as stallion, military horse, Dao horse, hunting horse, inferior horse and so on. "Er Ya" even listed 36 varieties of horses and their differences, such as the horse's hair color having black and white mix, yellow and white mix, red and white mix and so on. Jia Sixie said in his works "Qimin Yaoshu" that "grains ripe earlier or later, seedling is tall or low, the harvest is more or less, the quality is high or low, the rice tastes good or bad, the grain body is full or empty.", which not only showed the difference in harvest but also the variations of traits.

"Lunheng" written by Wang Chong also analyzed the biological variation. In the "Lunheng. Jiangrui", when refuting the superstition of the people in Phoenix, Kirin, Jiahe and other so-called "Auspicious things", he pointed out that Phoenix, Kirin and Jiahe were not special or mysterious creatures, but common beasts ,birds or grain variations. He said, "Auspicious things are all born in harmony, they are born in the regular class, but with strange nature." And many examples are borrowed to explain the biological variations. He said: "Yueshang contributed white pheasant, white pheasant was born to be white not because the species are so." For the so called "Auspicious things" Jiahe, Wang Chong believed it was a variation happened in common grains. He said: "Jiahe was born in grains, but with different grain ears." In Chinese ancient books, there are many records about grain branch variations. For example, according to "Houhan Shu. Guangwu Benji", the first year of Jianping period in the Western Han Dynasty (6 BC), Jiahe was found in Jiyang (currently Yi County, Shandong Province), carrying nine ears in one stem. According to the records of "Liangshu. Wudi Benji", in May of the fourth year of Liang Tianjian period (AD 505), Jiahe with twelve ears in one stem was found in Shuoyin $\mathrm{Li}$, Jiankang county (currently south of Jiangning County, Jiangsu Province). There are so many cases as that, it can be seen that the ancients had deep understanding of the branch variations of rice, wheat and other crops.

During the Song dynasties, with the development of gardening such as fruit trees, flowers, ornamental plants and animals, more abundant knowledge of genetic variation was accumulated Cai Xiang said in his works "Litchi Chart" (AD 1059) that: "Litchi tastes sweet, although from hundreds and thousands of trees, there are no the same taste." It indicated the individual differences in the same species. Liu Meng described 35 varieties of chrysanthemum in his works "Chrysanthemum Spectrum" (AD 1104). When analyzing the variation of chrysanthemum, he said: "The one with big flowers is chamomile, with small flowers and taste bitter is wild chrysanthemum, if planted in a fertile place, they will become one species, so the small can become big, the butter can become sweet. Like this the single leaf chrysanthemum can become a thousand leaves one." Occasionally single-leaf chrysanthemum can produce multiple-leaf one, this variation may be a mutation.

Song Yingxing of Ming Dynasty said in his works "Tiangong Kaiwu" that "There are many kinds of sorghum and millet, if they are kept in a distance hundreds of miles, their color, taste and shape will change, they are of general resemblance with small differences, and called different in names." It proved that the ancient people had a certain understanding of the generality of biological variation. And the "General resemblance with small differences" is a correct reflection of the overall biological variation in the nature, the offspring of parents are like their parent, but also differ in some points. Xia Zhichen of Ming Dynasty was expertise in peony cultivation, writing a works "Discussion on Bozhou Peony", which indicated "The soil in this place is good to plant flowers, regardless of gardener or landlord, as long as they like planting flowers, they can plant by seedlings or root graft. The best way is to take six-inch bud and graft it on the root of a low quality peony. In that year it grows one foot longer with one or two flowers. After two or three years it will be in full blossom. The similar situations all use this graft method. If the species is abnormal, its seeds may have sudden change." The theory of "If the species is abnormal, its seeds may have mutation" proves that about 400 years ago, Xia Zhichen had already used "mutation" to explain the variation of peony species, which was 300 years earlier than the "mutation" theory raised by the Dutch botanist De Vries.

\section{Understanding of the Relation between Genetic Variation and the Environment}

During the production and practice, ancient people had recognized the influence of environmental condition changes on the biological variation. Jia Sixie said in his works "Qimin Yaoshu" that when planting garlic, place small tiles on the bottom of ridges, put the garlic clove on the tile, and then cover it with soil. In this way the garlic shape is very special, flat wide and large. He was surprised at it, saying that it is "enough to be strange". Besides, he also said that at that time Shanxi (Bing State) had no garlic, and many went to get garlic seeds at Henan (Zhaoge). But after planting the garlic for a year, they only gained garlic with very small garlic cloves. On the contrary, the turnip roots in Shanxi were as big as bowl, even getting the turnip seeds from other places, as long as they were planted for one year, it would become large. Jia Sixie exclaimed: "The garlic cloves become small but the turnip root become big, the two things are on the contrary, it is very difficult to deduct its rule." Besides, the peas produced in Shanxi were planted in the east of the Jingxingkou, and the millets produced in Shandong were planted in Shangdang Huguan, Shangxi, both only grew but with no fruits. Jia Sixie said these were not stories but seen by eyes of his own. Finally, he concluded that these were caused by the differences in land conditions.

"Orange planted in Huainan is orange but becomes trifoliate orange if planted in Huaibei, which are similar in leaves but different in taste. why? Because the water and the soil are different." ("Yanzi Chunqiu"). Part II of "Guanzi. Diyuan" detailed the soil and specified the nature of soil and appropriate crops, varieties and other agricultural and sideline 
products. Wang Guan, in Song Dynasty, said in his works Yangzhou Peony Spectrum, "Currently Luoyang peony and Weiyang herbaceous peony both grow in natural conditions, but their sizes and colors changed with grafting and skills of workers, so the color and size differ around the world". Besides, he said, "The colors of flowers and the prosperity of leaves depended on the cultivation." It indicated that changing the living conditions can lead to variations.

Shen Kuo of Song Dynasty said in his works "Mengxi Bitan" that "In southern places the peaches and plums bear fruits in winter, in northern places peaches and plums bear fruits in summer, it is because of the earth and weather." Wang Zhen of Yuan Dynasty said in his works that "Nong Shu", "Every kind of species have an appropriate place to grow, those which should grow in Hebei and Shandong shall not be planted in Qingzhou and Xuzhou; those which should grow in Jingzhou and Yangzhou shall not be planted in Yongzhou and Yuzhou ... the grains quality differ because of soil and climate." The ancient people had found that creatures would mutate in different environments, so there are corresponding creatures in different environments.

\section{PRACTICAL APPLICATION OF CHINESE ANCIENT BIOGENETICS THOUGHT}

In ancient times, human being had cultivated plants and animals in line with the needs of their own according to the biogenetics and variation. During the agricultural and animal husbandry production, the people were always willing to keep individual plants and animals in variance which were beneficial to human beings, and make them continue reproduction. So after generations of selections, those selected creatures gradually get out of the wild state and become domestic animals or cultivated plants. For example, China was earlier to breed wild rice into cultivated rice, and one of the earliest countries to cultivate wild boars into domestic pigs and the earliest to cultivate ornamental goldfish.

\section{A. Artificial Selection of Breeding}

The book "Sisheng Zhishu" written in Han Dynasty, put forward specific requirements for a variety of crop seed selection, that is the wheat carrying big ear shall be selected; the millet carrying quality ear with pure color shall be selected. The "Qimin Yaoshu" not only proposed quality ears with pure color, but also harvested separately: planted in the seed field, and stored separately after harvest. In addition, in order to guarantee the breeding in ancient China, single plant selection method was adopted. According to the records of "Kangxi Jixia Gewu Bian", "Millet has colors yellow and white, some of the yellow stick but some not, only the white all do not stick. Seven years ago, in $\mathrm{Wu} \mathrm{La}$ (current in Jilin county, Jilin Province), there was a white millet in a tree hole, the local people planted the seeds and harvest endless millet with delicious taste. After Emperor Kangxi obtained this quality white millet seeds, he commanded the people to plant at villages, the results proved that the white millet had twice sized stems, leaves and ears than other species, and riped fast, so it was a good seed. Later the single plant selection method was used successfully to breed a high yield rare-ripe quality rice, named royal rice.
Another classic example of ancient artificial selection of breeding is the cultivation of goldfish. Goldfish originated in China, also known as "golden carp", similar to carp, but carrying mouth palpus, is an ornamental fish which evolved from carp fish. It might be possibly nurtured successfully in Song Dynasty. Su Dongpo, a famous poet of Northern Song Dynasty, wrote in a poem when visiting the West Lake, that "I know Nanping golden carp." Golden carp is a relatively primitive goldfish, and in the Southern Song Dynasty, goldfish gradually became a favorite ornamental animal. At that time, many of nobilities and monks competed to seek and build pools to breed gold carp for entertainment. Yue Ke, grandson of Yue Fei a famous leader in Southern Song Dynasty also described a golden carp breeding in "Ting Shi". He said, "Currently there are fish that can become gold color, crucian carp is the best, followed by carp. Nobilities normally built fish pools with stones and place them between the canopy windows for play. When asked the secret, they would not tell. The fish was raised with some red worms and after a hundred days all fish became golden color." According to the "Ting Shi", it can be seen that there had been a set of breeding methods of goldfish, and they had already know that small red worms (zooplankton in algae) are the favorite foods for goldfish.

From $13^{\text {th }}$ century to $16^{\text {th }}$ century, goldfish was gradually raised from pools to basins, and the success in feeding in basins made it further promoted and popularized. Zhang Qiande said in his works "Zhusha Yupu" (AD 1596) that "Most of the fish fans like raising cinnabar fish (goldfish), just like the best materials selected for construction, thousands of fish was selected every summer and raised in tens of vats. The bad fish was removed day by day until one or two left, and then raised in two or three vats. Raising more carefully and naturally will get the best goldfish." This large-scale careful selection cultivated many new varieties such as five-flower, two-tailed, double-anal fins, long-fins, raised eyeball, short body and so on. UP to the $19^{\text {th }}$ century, the people had already known consciously artificial selection. More varieties in variation appeared, and it was estimated to be more than 160 kinds, to which, Darwin paid more attentions, systematically describing the process and principle of artificial selection of goldfish in China in his works "the Origin of Species".

\section{B. Animal Hybridization}

Through the hybridization between the same species or even between different ones, some new varieties with desirable qualities usually will be produced, which is called heterosis. In the Spring and Autumn Period, a horse was crossed with a donkey to get a mule, a famous hybrid animal, which could be found in the "Lyushi Chunqiu". It was said in the "Lvushi Chunqiu. Aishi" that, "Zhao Jianzi has two white mules, and loves them very much"; the "Qimin Yaoshu - Raising Cow, Horse, Donkey and Mule" gave a much clear records of the heterosis, "Mule is normally produced by male horse and female donkey, if male donkey with female horse, it will be difficult to get mule. The mule is stronger and bigger than horse."; it was in "Bencao Gangmu" that "Mule is larger than donkey, and stronger than horse", Fang Yizhi said in his works Volume X of "Physics Tips" that "Mule is resistant to walk 
and not easy to be sick" and so on. The mule, produced by horse and donkey, owns the excellent traits of horse and donkey better than horse and donkey. From the horse, the mule gets a large body, running fast, strength, liveliness and so on, and from the donkey, it gets stable paces, uneasily to be excited, high endurance, resistance to coarse feeding. Up to now, this cross-breeding is still widely used in production and practice.

In Ming Dynasty, the heterosis was used for the silk production. Song Yingxing, a scientist of Ming Dynasty, said in his works "Tiangong Kaiwu" that "The cocoon color only has two kinds: yellow and white. There is a yellow cocoon but no white one in Sichuan, Shaanxi, Shanxi and Henan; yet, there is white cocoon but no yellow one at Jiahu. If making white male mate with yellow female, its offspring will become brown", besides, he added, "Currently some poor family make early male mating with late female, then get a new quality species which is very strange." The two records showed that silkworm raisers made hybridization of two groups of silkworms. First, hybridize the yellow silk male silkworm with white silk female silkworm; second, hybridize the early male silkworm with late female silkworm. As a result, the first group of hybridization produced brown silk hybrids, and the second group of hybridization produced quality variety. The so-called "early male mating with late female" is to hybridize the univoltine male silkworm with bivoltine female silkworm. Modern silkworm raising scientists' researches on silkworm genetic voltinism have shown that through the univoltine silkworm hybrid with the bivoltine silkworm, their first generation of hybridization has the same voltinism with their parental generation. If the parental female is univoltine, the first generation of hybridization will be also univoltine; if the parental female is bivoltine, the hybridization variety will be bivoltine. According to the hereditary law of silkworm hybridization, we can see that the quality variety produced by "early male mating with late female" mentioned in the "Tiangong Kaiwu" is a bivoltine silkworm. Under normal circumstances, feeding summer silkworm adopts "late silkworm" to spread the species. The bivoltine late silkworms often show fine traits as strong physique, high temperature endurance, suitable to feed in summer high temperature environment and so on. But this silkworm' silk volume is indeed lighter. And the early silkworm is better than that of the late one, whether in amount or quality of silk. But this kind of silkworm's physique is weak and low in high temperature resistance, meanwhile, for it is univoltine, it can not reproduce in summer under natural conditions. Through the hybridization of the two varieties, the hybrid varieties tend to integrate the good traits of parents. In Ming Dynasty Jiahu region, the silkworm raisers had found the advantages of hybrid varieties during the long-term practice, which was called quality variety.

\section{Plant Grafting}

Grafting technology was created initially by Chinese people. The grafting technology was used to cultivate fine varieties, develop fruit trees and flowers and preserve fine varieties, which was a great contribution of the Chinese people to the development of cash crop production. Chinese classical books as "Er Ya", "Qimin Yaoshu", "Shijing" and so on all had records of grafting technologies. Up to Jin and Yuan dynasties, Chinese people had created a series of grafting methods such as body grafting, root grafting, skin grafting, branch grafting, contact grafting and so on, and many ideas were exactly the same as modern grafting technologies. Han Yanzhi of Song Dynasty said in his works "Records of Orange that if the fine varieties of orange fails to be in grating in time, the flowers will not blossom and it will become citrus." It means that fine orange varieties, which are already grafted in the late fruit period must be grafted to cultivate new seedlings and update germplasm, in order to maintain its excellent traits, otherwise, it will grow into inedible citrus. The grafting methods were also developing in the production and practice. Han E of Tang Dynasty said in his works "Sishi Zuanyao - January" that "For tree grafting, as long as the tree stem is as big as axe handle or arm, the tree is able to be grafting, it is called tree rootstock. If the rootstock is big, cut it with one foot from the ground, if it is cut too close to the ground, the grafted tree will die. If smaller, cut it with 7 or 8 inches to the ground, if the rootstock is small but cut more, it will fail either", "When grafting, cut with the rootstock skin, insert deep and rush. The binding tightness shall be kept well. After grafting," take a natural piece of bark with half inch in width, wrap around the grafting place to prevent rain flow in". The above mentioned the names of trees and rootstock and indicated the relations between the rootstock size and the grafting place, as well as technical details of grafting. The understanding and application of grafting technologies was highly developed in Song Dynasty. The grafting technology was widely used in flower cultivation, Ouyang Xiu said in his works "About Peony in Luoyang" that "Every Luoyang family plants flowers but less has big trees, all because big trees can not grow well without grafting." Lu You said in his works "About Peony at Tianpeng" that "The flower farmers have grown fast, almost all of them take grafting as their major business", "They have methods in planting, grafting, picking and curing, which was called grass flower" The grafting method promoted the increase of peony varieties in Luoyang and Tianpeng, so Peony enjoyed the honor of the king of flowers. Su Song said in his works "Bencao Tujing" that "The reasons why the flowers are so strange are they get grafted in autumn and winter." From the above, we can see that the ancient Chinese people had already realized that the grafting is one of the technical measures to preserve flower and fruit tree varieties and quality.

\section{CONCLUSION}

Having a long history and splendid culture, China is an indispensable part of the world civilization, to which it has made important contributions. Chinese ancient sciences and technologies are contained in a large number of books and records, cohered in materialized, rich and varied cultural relics, and melted in a number of scientific and technological activities, and still maintained vigor till today. It needs to explore, organize and research deeply in order to reveal its profound and true contents. 


\section{REFERENCES}

[1] Luo Guihuan, Wang Zichun. Chinese History of Science and Technology: Biology Volume [M]. Beijing: Science Press, 2005.

[2] Wang Zichun. Chinese Ancient Understanding of Hiogenetics and Variation [J]. Studies In the History of Natural Sciences, 1989, 8 (3).

[3] Xi Zezong.Chinese Science and Technology History: Science Thought Volume [M]. Beijing: Science Press, 2001, 6.

[4] Institute of Natural Science History . Chinese Ancient Scientific and Technological Achievements [M]. China Youth Publishing Group, 1978.

[5] Luo Guihuan. Early Plant Domestication and the Origin of Chinese Civilization [J]. Agricultural Archaeology, 2003 (1).

[6] Xu Jisu, Chen Junhui, et al. General History of China [M]. Beijing: China Theatre Press , 2008, 8. 